between these two deficiency states. The concentration of pteroylglutamic acid used is critical, as it is known that the addition of $50 \mu \mathrm{g}$ per $\mathrm{ml}$ of marrow culture completely corrects the abnormality in both deficiency states (Metz et al., 1968).

\section{References}

Chanarin, I. (1969). Megaloblastic Anaemias. Oxford, Blackwell.
Corcino, J., Waxman, S., and Herbert, V. (1970). Annals of Internal Medicine, 73, 419.

Herbert, V., et al. (1973). British fournal of Haematology, 24, 713.

Killman, S.-A. (1964). Acta Medica Scandinavica, 175, 483.

Koutts, J., Van der Weyden, M. B., and Cooper, M. (1973). Australian and New Zealand fournal of Medicire, 3, 245.

Metz, J., et al. (1968). British fournal of Haematology, 14, 575

Van der Weyden, M., Rother, M., and Firkin, B. (1972). British fournal of Haematology, 22, 299.

Van der Weyden, M. B., Cooper, M., and Firkin, B. G. (1973). Blood, 41, 299.

Waxman, S., and Herbert, V. (1969 a). New England fournal of Medicine, $280,1316$.

Waxman, S., and Herbert, V. (1969 b). Federation Proceedings, 28, 627.

\title{
Iatrogenic Osteomalacia and Myopathy due to Phosphate Depletion
}

\author{
L. R. I. BAKER, \\ P. ACKRILL, \\ W. R. CATTELL, \\ T. C. B. STAMP, L. WATSON
}

British Medical fournal, 1974, 3, 150-152

\section{Summary}

In a patient receiving regular dialysis prolonged hypophosphataemia due to aluminium hydroxide therapy resulted in osteomalacia and severe proximal myopathy. Both osteomalacia and myopathy responded to correction of hypophosphataemia without vitamin D therapy.

\section{Introduction}

Both oesteomalacia and the proximal myopathy with which it is regularly associated respond to treatment with vitamin $\mathrm{D}$, and the myopathy is presumed to be a manifestation of vitamin $\mathrm{D}$ deficiency or of resistance to its action. We describe a patient receiving regular dialysis treatment in whom prolonged hypophosphataemia due to aluminium hydroxide therapy resulted in osteomalacia and severe proximal myopathy. It is of particular interest that both osteomalacia and myopathy responded to correction of hypophosphataemia without vitamin $\mathrm{D}$ therapy.

\section{Case Report}

A 26-year-old chromatin positive woman with multiple congenital defects (congenital absence of vagina and uterus, cervicothoracic spinal fusion, webbing of the neck, and a left Sprengel shoulder deformity) began regular dialysis treatment in October 1969. Six months previously she had presented with uraemia, and an intravenous pyelogram showed a very small left kidney and a small right kidney with a bifid renal pelvis. There was no obstruction and the appearances were consistent with congenital renal dysplasia. She received initially two 14-hour single pass haemodialyses a week using a Kiil dialyser and from December 1970 three 10-hour dialyses a week at home. Her diet contained about $500 \mathrm{mg}$ calcium and 180

St. Bartholomew's Hospital, London EC1A 7BE

L. R. I. BAKER, M.D., M.R.C.P., Consultant Nephrologist
P. ACKRILL, M.B., M.R.C.P., Senior Registrar

W. R. CATTELL, M.D., F.R.C.P., Consultant Nephrologist

\section{University College Hospital, London WC1E 6BT}

T. C. B. STAMP, M.D., M.R.C.P., Wellcome Research Fellow (Present appointment: Consultant Physician, Royal National Orthopaedic Hospital,

L. WATSON, M.R.C.P., F.R.A.C.P., Consultant Physician 

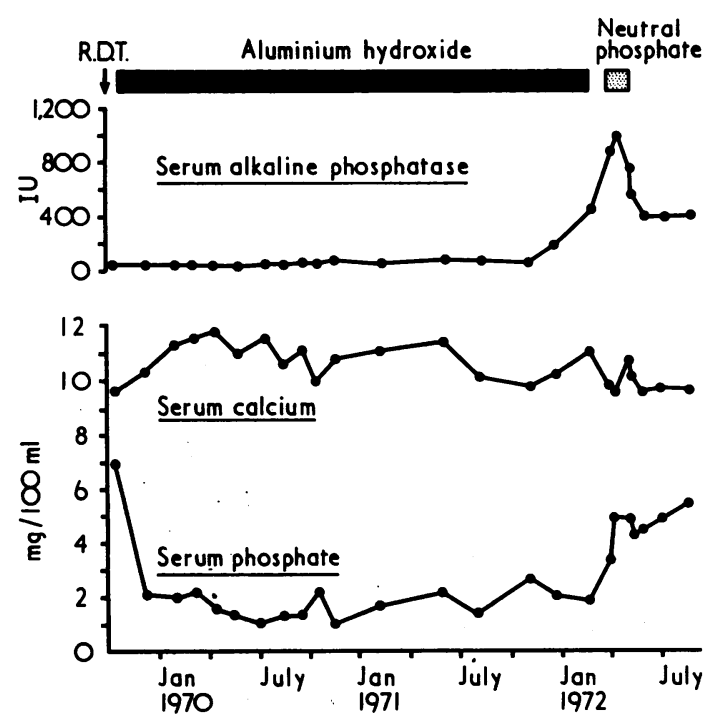

FIG. 2-Changes in serum calcium, phosphate, and alkaline phosphatase during treatment with aluminium hydroxide.

showed an increased tendency to polyphasic potentials but were of normal amplitude and duration.

She had had prolonged hypophosphataemia (serum phosphate regularly less than $2.0 \mathrm{mg} / 100 \mathrm{ml}$ ) since shortly after starting treatment with aluminium hydroxide. Alkaline phosphatase levels had been slightly raised from May 1971, and had risen sharply from November 1971 (fig. 2). There had been considerable fluctuation in serum calcium levels since the beginning of regular dialysis treatment. Blood samples were taken immediately before dialysis without fasting, and in these circumstances our normal range for serum calcium is $9.0-11.0 \mathrm{mg} / 100 \mathrm{ml}$. Oocasionally values in excess of $11.0 \mathrm{mg} / 100 \mathrm{ml}$ were abserved (fig. 2). Peripheral venous parathyroid hormone (PTH) level was $1.7 \mathrm{ng} / \mathrm{ml}$. This was measured by a standard radioimmunoassay as described previously by Davies et al. (1973) using bovine PTH and guinea pig antiserum BW211/ 32 supplied by the Wellcome Foundation. This assay system has shown good clinical validation. The upper limit in normal subjects is $0.8 \mathrm{ng} / \mathrm{ml}$. Plasma 25-hydroxycholecalciferol (25-HCC) level was normal at $11 \mathrm{ng} / \mathrm{ml}$ (determined by the method of Haddad and Chyu (1971)).

Aluminium hydroxide therapy was stopped and neutral phosphate mixture $(0.5 \mathrm{~g}$ elemental phosphorus daily) was begun. Plasma phosphate rose rapidly and the phosphate supplement was stopped after three weeks. The plasma calcium levels fell reciprocally. Within six weeks of stopping aluminium hydro-

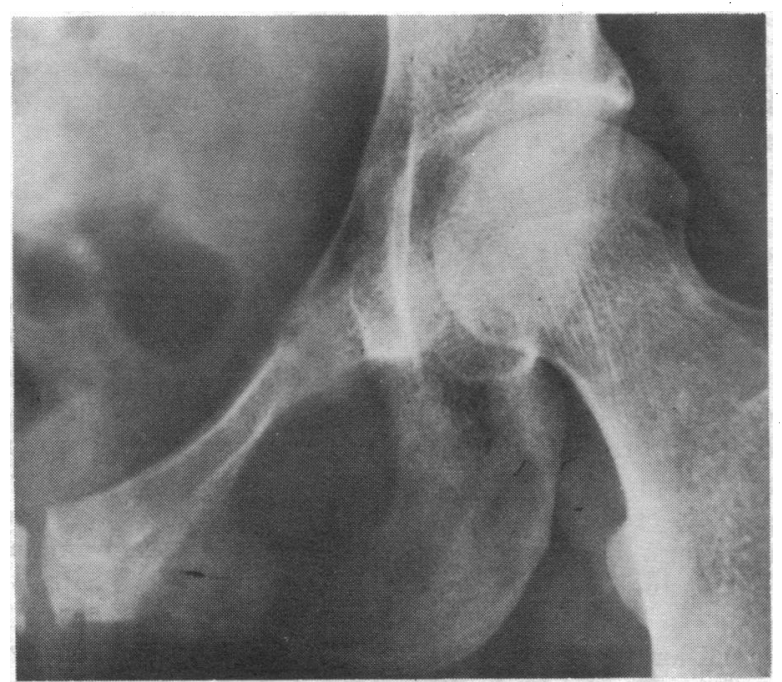

FIG. 3-X-ray picture of pelvis in March 1972 showing development of Looser's zone. xide muscle weakness and bone pain had disappeared, and she was able to rise unaided and carry out her housework normally. $X$-ray pictures of the pelvis taken in June 1972 showed healing of Looser's zones (fig. 4). For the first time subperiosteal erosions were visible in the phalanges. Plasma PTH level had risen to $4.0 \mathrm{ng} / \mathrm{ml}$ and plasma $25-\mathrm{HCC}$ level remained normal at $16 \mathrm{ng} / \mathrm{ml}$. After a sharp initial rise, characteristic of healing osteomalacia, alkaline phosphatase fell to values similar to those present before aluminium hydroxide was withdrawn. The patient received a sucoessful cadaveric renal transplant in December 1972.

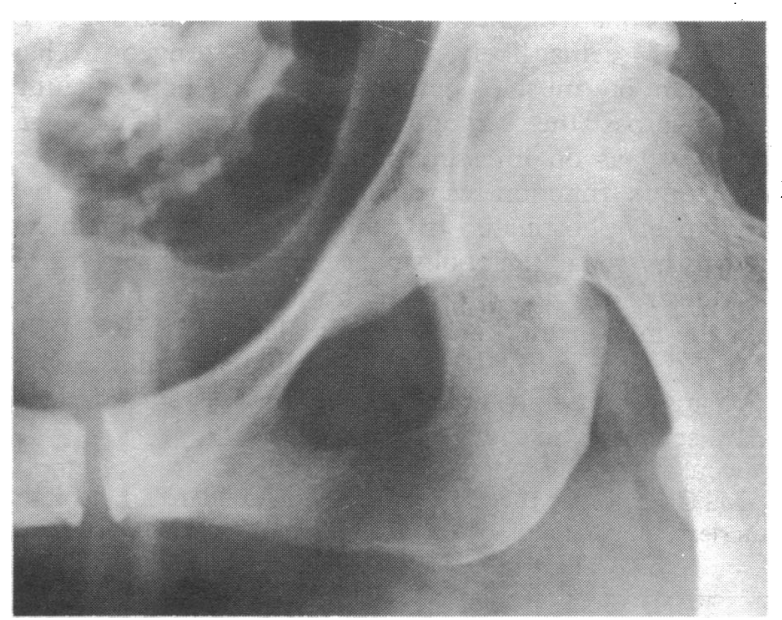

FIG. 4-X-ray picture of pelvis in June 1972 showing healing after correction of hypophosphataemia.

\section{Discussion}

Osteomalacia is seen occasionally in patients on regular dialysis treatment with normal or raised plasma phosphorous levels (Siddiqui and Kerr, 1971). By contrast we observed osteomalacia in association with hypophosphataemia. This and the rapid response to phosphate repletion indicates that the osteomalacia was due predominantly to hypophosphataemia in our patient.

Despite the ease with which rickets may be produced by phosphate depletion in experimental animals this cause is very rare in man. In patients with normal renal function osteomalacia has followed uncontrolled self medication with aluminium hydroxide for dyspepsia (Lotz et al., 1964; Dent and Winter, 1974). Osteomalacia has also been produced in this way in patients with renal failure (Dent et al., 1961; Dodge and Travis, 1965). Aluminium hydroxide is being used increasingly to prevent ectopic calcification and osteitis fibrosa in patients on regular dialysis, and our case underlines the need for careful avoidance of overtreatment.

Cure of both myopathy and osteomalacia, as shown clinically and radiographically, resulted from phosphate repletion in our patient though radiolographical evidence of hyperparathyroidism appeared after treatment, and serum alkaline phosphatase levels did not return to normal. The rise in circulating PTH levels presumably resulted from the simultaneous fall in serum calcium during phosphate repletion (Bricker et al., 1969).

The cure of myopathy without vitamin $\mathbf{D}$ therapy raises the question of the relation between vitamin $D$ and hypophosphataemia in the pathogenesis of the myopathy. Low plasma phosphorus levels are not always found in osteomalacic myopathy, and when hypophosphataemia is present treatment with vitamin $D$ in pharmacological doses may cure the myopathy without affecting the hypophosphataemia. This phenomenon is seen in primary hypophosphataemic osteomalacia in adults (Dent and Stamp, 1971) though treatment by phosphate alone may also improve the myopathy (Nagant 
de Deuxchaisnes and Krane, 1967). Further evidence that there is no simple relation between prolonged hypophosphataemia and myopathy is found in the common $\mathrm{X}$ linked form of hereditary rickets, in which myopathy is always absent despite lifelong hypophosphataemia (Dent et al., 1973).

Better understanding of these problems may result from recent observations that the metabolism of vitamin $D$ is closely related to that of phosphate at cellular level. The production by kidney of 1:25-dihydroxycholecalciferol, the biologically active hormonal form of vitamin $D$, from 25HCC (Fraser and Kodicek, 1970) may be regulated by intracellular phosphate concentration (Tanaka and De Luca, 1973). If, as seems likely, vitamin $D$ is proved to have a direct action on muscle, perhaps in controlling calcium ion transport across the sarcoplasmic reticulum (Curry et al., 1974), as well as on intestine and bone it would not be surprising if this function were also regulated in part by the availability of phosphate. In patients receiving maintenance haemodialysis renal metabolism of vitamin $\mathrm{D}$ may be defective (Mawer et al., 1971). Thus, though both dietary vitamin D intake and levels of circulating 25-HCC (Stamp et al., 1972) were normal in our patient her diminished renal metabolism of vitamin D may have made her muscles particularly sensitive to hypophosphataemia.

We would like to acknowledge the help of $\mathrm{Mr}$. K. Agnew and Sister M. Chappell at the dialysis unit, St. Leonard's Hospital; Mr. P. Saunders, department of chemical pathology, St. Bartholomew's
Hospital; Mr. W. D. Tredinnick of the department of medical illustration, St. Bartholomew's Hospital; Dr. P. D. Byers, department of morbid anatomy, Royal National Orthopaedic Hospital; and Dr. P. K. Thomas, consultant neurologist, Royal Free Hospital, who performed the electromyography and nerve conduction studies.

Requests for reprints should be sent to Dr. L. R. I. Baker.

\section{References}

Bricker, N. F., et al. (1969). Archives of Internal Medicine, 123, 543.
Curry, O., Francis, M. J. O., and Smith, R. (1974). Clinical Science and Molecular Biology. In press.

Davies, D. R., et al. (1973). Lancet, 1, 1079.

Dent, C. E., Harper, C. M., and Philpott, G. R. (1961). Quarterly fournal of Medicine, 30, 1 .

Dent, C. E., and Stamp, T. C. B. (1971). Quarterly fournal of Medicine, 64, 303.

Dent, C. E., Round, J. M., and Stamp, T. C. B. (1973). In Clinical Aspects of Metabolic Bone Disease, ed. B. Frame, A. M. Parfitt, and H. Duncan. p. 427. Amsterdam, Excerpta Medica.

Dent, C. E., and Winter, C. (1974). British Medical fournal, 1, 551.

Dodge, W. F., and Travis, L. B. (1965). Paediatrics, 35, 792.

Fraser, D. R., and Kodicek, E. (1970). Nature 228, 764.

Haddad, J. G., and Chyu, K. J. (1971). Fournal of Clinical Endocrinology and Metabolism, 33, 992.

Lotz, M., Ney, R., and Bartter, F. C. (1964). Transactions of the Association of American Physicians, 77, 281.

Mawer, E. B., et al. (1971). Nature, 232, 188.

Nagant de Deuxchaisnes, E., and Krane, S. M. (1967). American fournal of Medicine, 43, 508.

Siddiqui, J., and Kerr, D. N. S. (1971). British Medical Bulletin, 27, 153. Stamp, T. C. B., et al. (1972). British Medical fournal, 4, 9.

Tanaka, Y., and De Luca, H. F. (1973). Archives of Biochemistry and Biophysics, 154, 566.

\title{
Plasma TSH and Serum T-4 Levels in Long-term Follow-up of Patients Treated with ${ }^{131} I$ for Thyrotoxicosis
}

\author{
A. D. TOFT, W. J. IRVINE, W. M. HUNTER, J. SETH
}

British Medical fournal, 1974, 3, 152-153

\section{Summary}

In February $197258 \%$ of patients euthyroid after iodine131 therapy given for thyrotoxicosis between 1954 and 1966 had a high plasma TSH $(>7 \cdot 4 \mu \mathrm{U} / \mathrm{ml})$ and $42 \%$ a normal plasma TSH level. A group of 69 of the euthyroid patients with high plasma TSH levels $(25 \cdot 0 \pm 2.0 \mu \mathrm{U} / \mathrm{ml})$ in 1972 were re-examined 15 and 24 months later. The mean plasma TSH in the 66 patients remaining euthyroid at 15 months was $22.6 \pm 1.8 \mu \mathrm{U} / \mathrm{ml}$, while three patients had become hypothyroid. At 24 months 64 of the patients were still available for study, of whom 61 remained euthyroid with a mean plasma TSH of $21.6 \pm 2.0$ $\mu \mathrm{U} / \mathrm{ml}$, and a further three had become hypothyroid.

All of a group of 61 of the euthyroid patients with normal plasma TSH levels $(4 \cdot 0 \pm 0 \cdot 2 \mu \mathrm{U} / \mathrm{ml})$ in 1972 remained euthyroid at 24 months with a mean plasma TSH of

\footnotetext{
Department of Endocrinology and University Department of Therapeutics, Royal Infirmary, Edinburgh, EH3 9YW A. D. TOFT, B.SC., M.R.C.P., Senior Registrar

W. J. IRVINE, D.SC., F.R.C.P., Reader

M.R.C. Radioimmunoassay Team, Edinburgh

W. M. HUNTER, PH.D., Head of Team

University Department of Clinical Chemistry, Edinburgh J. SETH, PH.D., Lecturer
}

$4 \cdot 1 \pm 0 \cdot 3 \mu \mathrm{U} / \mathrm{ml}$, though the plasma TSH level had become slightly raised in three.

The mean serum $T-4$ level in the euthyroid patients with a high plasma TSH was significantly lower, though still in the normal range, than that in the euthyroid patients with a normal plasma TSH both in 1972 and in 1974.

Since no patient with a normal plasma TSH level after iodine-131 treatment six to 18 years earlier for thyrotoxicosis developed hypothyroidism over a two-year period, the follow-up of such patients need not be so rigorous as that of similarly treated euthyroid patients with raised plasma TSH levels in whom hypothyroidism developed at the rate of $5 \%$ per year.

\section{Introduction}

The incidence of hypothyroidism after ${ }^{131} \mathrm{I}$ treatment of thyrotoxicosis is greatest in the first year $(7-22 \%)$ and continues at $2-4 \%$ a year (Hagen, 1968). Toft et al. (1974) found a low serum thyroxine ( $T-4)$ level to be a sensitive index of developing hypothyroidism in the early months after radioiodine therapy but it has not yet proved possible, using conventional tests of thyroid function, to predict when or in whom hypothyroidism will occur in later years. This results in the follow-up of large numbers of patients. A high plasma thyrotrophin (TSH) level is considered to be a good index of thyroid failure but is not uncommon after ${ }^{131}$ I treatment of thyrotoxicosis and may persist in euthyroid patients for many months (Slingerland et al., 1972; Toft et al., 1973). The present paper reports the clinical and biochemical 